\title{
Calcium and Phosphate Transport in Isolated Segments of Rabbit Henle's Loop
}

\author{
Antonino S. Rocha, Jose B. Magaldi, and Juha P. KokKo \\ From Unidade de Doencas Renais, Department de Clinica Medica, Hospital das Clinicas da \\ Faculdade de Medicina da Universidade de Sao Paulo Sao Paulo, Brasil and Department of \\ Internal Medicine The University of Texas Health Science Center Southwestern Medical \\ School Dallas, Texas 75235
}

A B S T RACT Calcium and phosphate transport was examined in rabbit thin descending, thin ascending, and thick ascending limbs of Henle by in vitro perfusion of isolated tubular segments. Permeability coefficients for these segments with ${ }^{45} \mathrm{Ca}$ and ${ }^{32} \mathrm{PO}_{4}$ were determined for both lumen-to-bath and bathto-lumen directions. Both the thin descending and thin ascending limbs were found to be relatively impermeable to both ${ }^{45} \mathrm{Ca}$ and ${ }^{32} \mathrm{PO}_{4}$. In neither segment were we able to show evidence for net transport of calcium or phosphate. In contrast, the thick ascending limb of Henle showed a decrease in calcium lumen-to-bath concentration from $0.97 \pm 0.02$ to 0.88 \pm 0.02 when perfused at $4.8 \mathrm{nl} \mathrm{min}{ }^{-1} .{ }^{45} \mathrm{Ca}$ lumen-tobath and bath-to-lumen fluxes were 19.96 \pm 1.05 and $9.89 \pm 0.02 \mathrm{peq} \cdot \mathrm{min}^{-1} \cdot \mathrm{cm}^{-1}$, respectively, and the potential difference was $+3.8 \pm 0.3 \mathrm{mV}$ (lumen positive). The observed calcium flux ratio was significantly higher than that predicted by Ussing's equation. When ouabain was added to the bath the potential difference fell to $+1.1 \pm 0.3 \mathrm{mV}$, whereas the calcium efflux was only slightly diminished $(29.5 \pm 5.3-23.7 \pm 5.1$ peq $\left.\cdot \mathrm{cm}^{-1} \cdot \mathrm{min}^{-1}\right)$. Ouabain had no effect on the influx of $\mathrm{Ca}$ across the thick ascending limb of Henle. There was no net transport of phosphate across the thick ascending limb. Phosphate permeability was exceedingly low bidirectionally across the thick ascending limb. Our findings indicate: $(a)$ all segments of Henle's loop are relatively impermeable to calcium and phosphate; $(b)$ net transport of phosphate seems to be absent in Henle's loop; $(c)$ net calcium reabsorption, which cannot be explained by

Preliminary reports of a portion of this work have been presented at the VI International Congress of Nephrology. 1975. Firenze, Italy.

Received for publication 7 May 1976 and in revised form 13 January 1977. passive mechanisms, occurs in the thick ascending limb.

\section{INTRODUCTION}

It is now generally accepted that both calcium and phosphate are reabsorbed in that portion of the proximal convoluted tubule accessible to micropuncture (1-11). Furthermore, micropuncture studies have suggested that net calcium reabsorption takes place between the late part of the proximal convoluted tubule and early portions of the distal tubule (1,3-7); whereas, there does not seem to be any net transport of phosphate between these two micropuncture sites (3-8). However, no previous studies have directly examined the segmental transport properties of the loop of Henle with respect to calcium and phosphate. It, therefore, was the purpose of the present studies to examine the characteristics of calcium and phosphate transport in the thin descending (DLH), ${ }^{1}$ thin ascending (tALH), and thick ascending (TALH) limbs of Henle utilizing the technique where isolated segments of rabbit nephrons are perfused in vitro (12).

\section{METHODS}

Female New Zealand white rabbits were fed a standard laboratory chow diet and had free access to water before sacrifice. The appropriate tubule segments were dissected from a small slice of kidney obtained immediately after sacrifice. During dissection the kidney slice was immersed in a dish of chilled rabbit serum, oxygenated and kept at pH 7.4 by gassing with $95 \% \mathrm{O}_{2}$ and $5 \% \mathrm{CO}_{2}$. After dissection, the isolated tubular segments were transferred to a temperature controlled perfusion chamber which was kept at $37^{\circ} \mathrm{C}$. Positive identification of the thin descending and

${ }^{1}$ Abbreviations used in this paper: $\mathrm{CP}$, collected-to-perfusate; DLH, thin descending limb of Henle; PD, potential difference; tALH, thin ascending limb of Henle; TALH, thick ascending limb of Henle. 
thin ascending limbs was accomplished by observing their transition to pars recta and thick ascending limbs, respectively (13). The two ends of the tubular segments were sealed into the glass pipettes with Sylgard 184 (Dow Corning Corp., Midland, Mich.). Unless otherwise specified, $\mathrm{NaCl} / \mathrm{HCO}_{3}$ buffer (composition in $\mathrm{mM}: \mathrm{NaCl}, 115 ; \mathrm{NaHCO}_{3}$, 25; $\mathrm{Na}$ acetate, $10 ; \mathrm{KCl}, 5 ; \mathrm{CaCl}_{2}, 1.0 ; \mathrm{MgSO}_{4}, 1.2$; $\mathrm{NaH}_{2} \mathrm{PO}_{4}, 1.2$; glucose, 5.5) was used as a bath and perfusion solution. Pre-equilibration of perfusion solution with $95 \%$ $\mathrm{O}_{2}$ and $5 \% \mathrm{CO}_{2}$, and continuous bubbling of bath with the same gas mixture maintained the $\mathrm{pH}$ of both fluids at 7.4. At this $\mathrm{pH}$ approximately $80 \%$ of the total calcium in both perfusate and bath was in the ionized form (14). The tubular perfusion rate was controlled by varying the height of a column of water connected to the end of the perfusion pipette. Inside tubular diameter was measured from photographs obtained during the experiment. Timed tubular fluid samples were collected for analysis under mineral oil by aspiration into a calibrated pipette. All measurements were obtained 90-120 min after the initiation of perfusion of a given nephron segment.

Net water reabsorption (Jv) was measured with $\left[{ }^{14} \mathrm{C}\right]$ or $\left[{ }^{3} \mathrm{H}\right]$ inulin or $\left[{ }^{125} \mathrm{I}\right]$ iothalamate in the perfusate as a volume marker. Jv was calculated as $\mathrm{Vi}-\mathrm{Vo} / \mathrm{L}$ where $\mathrm{Vi}$ is the perfusion rate, Vo the collection rate and $L$ the length of tubule studied. (Tubule length can be measured to within $0.05 \mathrm{~mm}$ with a precalibrated micrometer in one eyepiece of the inverted microscope used to observe perfusion.) Vo was directly measured by using the collection time while Vi was calculated as total counts per minute of volume marker in collected fluid divided by the product of volume marker counts per minute per nanoliter in perfusion fluid and collection time.

The permeability coefficient for calcium and phosphate was determined by measuring the rate of appearance or disappearance from the luminal fluid of the respective isotope added either to the bath or to the perfusate. When bidirectional fluxes of calcium were measured in the same tubule, successive determinations of each unidirectional flux were made. In these experiments perfusate was changed by introducing new perfusate through a small polyethylene tube that had been advanced to the tip of the perfusion pipette. In the initial three consecutive collections ${ }^{45} \mathrm{Ca}$ was added to the bath, and its appearance rate into the collected fluid was monitored. ${ }^{45} \mathrm{Ca}$ was then removed from the bath by exchanging it at least three times with new bath fluid containing no isotope. Perfusate containing ${ }^{45} \mathrm{Ca}$ was then introduced into the perfusion pipette as described above. Completeness of bath and perfusate exchange was monitored by sampling each. After at least a 30 -min equilibration time, ${ }^{45} \mathrm{Ca}$ efflux was measured during three successive collections.

In the thin descending and thin ascending limb the unidirectional isotopic fluxes were expressed in terms of apparent permeability coefficient according to the following expression (15):

$$
P_{1 b}=\frac{V i-V o}{A}\left(\frac{\ln \mathrm{Ci} / \mathrm{Co}}{\ln V_{i} / V_{0}}+1\right) \text {, }
$$

where $\mathrm{Vi}$ is the perfusion rate; $V_{0}$, collection rate; $C_{i}$, counts per minute per milliliter of isotope in the perfusate; $C_{0}$, counts per minute per millimeter of isotope in collected fluid and $A$, area of the tubule calculated from the length of tubule and inside diameter.

In experiments with no net water reabsorption, the permeabilities were calculated according to (15):

$$
P_{1 b}=\frac{V i}{A} \ln \left(\frac{C i}{C o}\right)
$$

The apparent isotopic permeability coefficient, measured from bath to lumen, was obtained from the influx rate of ${ }^{45} \mathrm{Ca}$ and ${ }^{32} \mathrm{PO}_{4}$ according to the expression (16):

$$
\mathrm{P}_{\mathrm{bl}}=\frac{\mathrm{Vi}(\mathrm{Cl})}{\mathrm{A}(\overline{\mathrm{Cb}-\mathrm{Cl})}} \text {, }
$$

where $\mathrm{Cb}$ and $\mathrm{Cl}$ are concentrations of the corresponding isotopes in the bath and collected fluid, respectively. $(\overline{\mathrm{Cb}}-\mathrm{Cl})$ is the logarithmic mean concentration gradient between the bath and collected fluid isotope concentration.

In those experiments in which the bidirectional fluxes were measured successively in the same tubule, the bath to lumen permeability coefficient $\left(\mathrm{P}_{\mathrm{bl}}\right)$ was calculated by (13):

$$
\mathrm{P}_{\mathrm{bl}}=\frac{\mathrm{Co}}{\mathrm{Cb}}\left(\frac{\mathrm{P}_{\mathrm{lb}}}{1-\exp \left(\frac{-\mathrm{A} \mathrm{Plb}}{\mathrm{V}}\right)}\right) \text {, }
$$

where $\mathrm{V}$ is the mean flow rate, $(\mathrm{Vi}+\mathrm{Vo}) / 2$.

To determine the capacity of thin descending limb to maintain a calcium and phosphate lumen to bath concentration gradient, segments of thin descending limb were perfused with artificial solution, $287 \operatorname{mos} \mathrm{M} / \mathrm{kg}$, against two types of bath. During the control periods, the bath was isosmolar $\mathrm{NaCl} / \mathrm{HCO}_{3}$ solution, while during the experimental periods, the bath osmolality was increased by addition of $\mathrm{NaCl}$. The collected to perfused concentration ratio of the isotopes $\left({ }^{45} \mathrm{Ca}\right.$ or $\left.{ }^{32} \mathrm{PO}_{4}\right)$ was compared to the ratio of increase in volume marker when the osmotic gradient was imposed across the tubular epithelium. In those experiments with ${ }^{45} \mathrm{Ca}$ in the perfusion solution, the perfusate was: $\mathrm{NaCl}, 145 \mathrm{mM} ; \mathrm{KCl}, 5 \mathrm{mM} ; \mathrm{CaCl}_{2}, 1.0 \mathrm{mM} ; \mathrm{MgSO}_{4}$, $1.2 \mathrm{mM}$; but without $\mathrm{PO}_{4}$ or $\mathrm{HCO}_{3}$. This composition was used to maintain the calcium virtually $100 \%$ ionized.

To determine whether the thick ascending limb can establish a lumen-to-bath calcium gradient, ${ }^{45} \mathrm{Ca}$ was added to $\mathrm{NaCl} / \mathrm{HCO}_{3}$ solution - a portion of which was used as perfusate and a portion as bath. The specific activity of ${ }^{45} \mathrm{Ca}$ was thus identical in the perfusate and bath. Therefore, a change in the counts of ${ }^{45} \mathrm{Ca}$ per nanoliter in the collected fluid with respect to the perfusate would signify a change in the chemical concentration of calcium, assuming that ${ }^{45} \mathrm{Ca}$ is a perfect tracer. The bathing fluid counts per nanoliter were closely monitored and kept constant by the addition of appropriate amounts of water to the bath to counteract the effects of evaporation. A sufficient amount of isotope was used so that collected samples counts per minute were always greater than $\mathbf{5 0}$ times the background (counts per minute).

Transtubular potential difference (PD) was measured in these studies utilizing calomel half cells (Beckman Instruments, Inc., Fullerton, Calif.) and a circuit identical to the one in which the PD of the thick ascending limb has been previously measured (17).

The radioactivity of ${ }^{125} \mathrm{I}$, was measured with a Nuclear Chicago gamma counter (Nuclear Chicago Corp., Des Plaines Ill.) and ${ }^{32} \mathrm{PO}_{4},\left[{ }^{3} \mathrm{H}\right]$ inulin, $\left[{ }^{14} \mathrm{C}\right]$ inulin, ${ }^{36} \mathrm{Cl}$, and ${ }^{45} \mathrm{Ca}$, were measured by using a Beckman liquid scintillation counter employing Aquasol Universal LSC Cocktail (New England Nuclear, Boston, Mass.). After background subtraction, counts were corrected for incomplete discrimination between the two channels. 
The sources of isotopes were: $\left({ }^{125} \mathrm{I}\right)$ iothalamate, (glofil125), Abbott Laboratories, N. Chicago, Ill.; [ $\left.{ }^{14} \mathrm{C}\right]$ carboxyl inulin-carboxyl, $\left[{ }^{3} \mathrm{H}\right]$ methoxy inulin-methoxy, ${ }^{36} \mathrm{Cl}$ and ${ }^{45} \mathrm{Ca}$, New England Nuclear; $\mathrm{NaH}_{2}{ }^{32} \mathrm{PO}_{4}$, Instituto de Energia Atomica, Sao Paulo, Brasil.

The results are expressed as mean \pm standard error. The data for each tubule includes the mean of two to four collection periods per tubule depending on the experimental protocol. All results were tested for significance with Student's $t$ test.

\section{RESULTS}

Thin descending limb. The permeability coefficients for ${ }^{45} \mathrm{Ca}$ were determined under conditions of zero net transport of fluid with $\mathrm{NaCl} / \mathrm{HCO}_{3}$ buffer $(\mathrm{pH} 7.4)$ as the perfusate and bath. The results of nine experiments are summarized in Table I and indicate the relatively low permeability of ${ }^{45} \mathrm{Ca}$ from bath to lumen $\left(0.92 \pm 0.28 \times 10^{-5} \mathrm{~cm} \cdot \mathrm{s}^{-1}\right)$ as well as from lumen to bath $\left(0.76 \pm 0.41 \times 10^{-5}\right.$ $\left.\mathrm{cm} \cdot \mathrm{s}^{-1}\right)$. Under these experimental conditions there was no evidence of net calcium transport. Experiments were conducted to determine if there is significant efflux of ${ }^{45} \mathrm{Ca}$ when the thin descending limb is exposed to a hyperosmotic bath (to simulate in vivo conditions of osmotic water extraction). In these experiments the collected to perfused ratio of ${ }^{45} \mathrm{Ca}$ counts per minute was compared to the collected to perfused volume marker ratio during conditions in which the bath was isosmotic and during conditions in which the bath was hyperosmotic (via $\mathrm{NaCl}$ addition to bath). As stated previously the perfusate composition was such that all of the calcium was in its ionized form. Fig. 1 is a plot of the col-

TABLE I

Calcium Permeability in the Thin Descending Limb of Henle's Loop

\begin{tabular}{ccccccc}
\hline \multicolumn{3}{c}{ Bath-to-lumen } & & \multicolumn{3}{c}{ Lumen-to-bath } \\
\cline { 1 - 2 } \cline { 5 - 6 } $\begin{array}{c}\text { Exp } \\
\text { no. }\end{array}$ & $\begin{array}{l}\text { Tubular } \\
\text { length }\end{array}$ & $\mathrm{P}_{45 \mathrm{ca}}$ & & $\begin{array}{c}\text { Exp } \\
\text { no. }\end{array}$ & $\begin{array}{c}\text { Tubular } \\
\text { length }\end{array}$ & $\mathrm{P}_{45} \mathrm{ca}$ \\
\hline & $m m$ & $\times 10^{-5} \mathrm{~cm} \cdot \mathrm{s}^{-1}$ & & $\mathrm{~mm}$ & $\times 10^{-5} \mathrm{~cm} \cdot \mathrm{s}^{-1}$ \\
1 & 0.90 & 1.81 & & 1 & 1.50 & -0.44 \\
2 & 1.30 & 1.34 & & 2 & 1.00 & 0.92 \\
3 & 2.10 & 0.63 & & 3 & 1.50 & 1.22 \\
4 & 1.46 & 0.51 & & 4 & 1.40 & 1.34 \\
5 & 1.20 & 0.32 & & & \\
Mean & & 0.92 & Mean & & 0.76 \\
SE & & 0.28 & & $\mathrm{SE}$ & & 0.41 \\
\hline
\end{tabular}

Permeability was measured by adding ${ }^{45} \mathrm{Ca}$ to the perfusate (P. lumen-to-bath) or in the bath (P. bath-to-lumen). Perfusion rate was $10 \mathrm{nl} . \mathrm{min}^{-1}$. Each value is the mean of three or more collections from a single tubule.

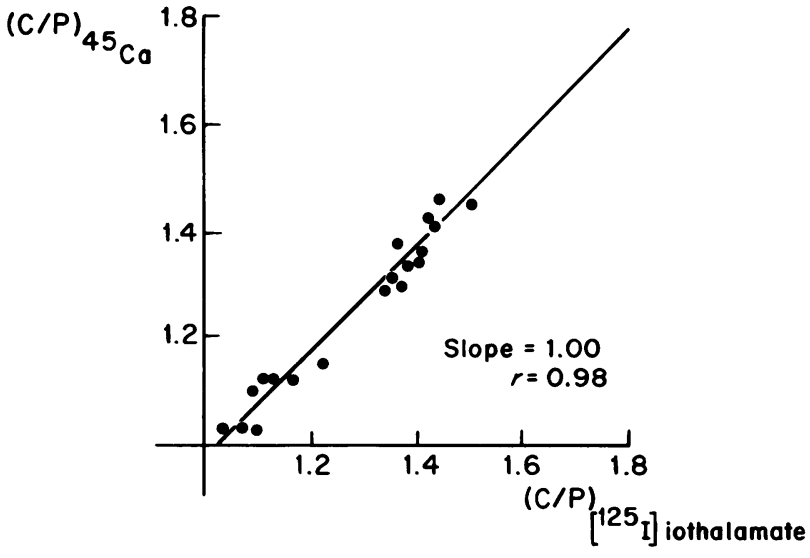

Figure 1 Correlation between fractional increase in calcium concentration $\left([\mathrm{C} / \mathrm{P}]^{45} \mathrm{Ca}\right)$ to fractional increase in volume marker $\left([\mathrm{C} / \mathrm{P}]\left[{ }^{125} \mathrm{I}\right]\right.$ iothalamate) in the thin descending limb of Henle's loop under conditions of induced net fluid efflux secondary to imposed osmotic gradient.

lected-to-perfusate $(\mathrm{C} / \mathrm{P}){ }^{45} \mathrm{Ca}$ versus the $\mathrm{C} / \mathrm{P}{ }^{125} \mathrm{I}$ glofil. As can be seen, a rise in volume marker ratio was associated with an identical rise in ${ }^{45} \mathrm{Ca}$ ratio (slope 1.00 correlation coefficient 0.98 ). Thus, with significant net osmotic water abstraction from the thin descending limb of Henle, calcium efflux was not increased. The epithelium, therefore, is able to maintain a passively generated transepithelial calcium concentration gradient.

The apparent permeability to phosphate, from lumen to bath was determined by the disappearance of $\mathrm{H}_{2}{ }^{32} \mathrm{PO}_{4}$ added to the perfusate. The calculated value $\left(-0.10 \pm 0.33 \times 10^{-5} \mathrm{~cm} \cdot \mathrm{s}^{-1}\right)$ is not statistically different from zero (Table II). However, the bath-tolumen permeability calculated from the influx of $\mathrm{H}_{2}{ }^{32} \mathrm{PO}_{4}$ added to the bath was $1.01 \pm 0.32 \times 10^{-5}$ $\mathrm{cm} \cdot \mathrm{s}^{-1}$. Both of these values indicate that the thin descending limb is relatively impermeable to phosphate. ${ }^{2}$

Low phosphate permeability in the presence of hyperosmotic bath is noted in Fig. 2, which represents a series of four experiments where segments of thin descending limb were studied successively during isosmotic conditions (zero net water reabsorption) and during osmotic water abstraction generated by $\mathrm{NaCl}$ addition to bath. The values obtained were

2 The statistically significant difference between lumento-bath and bath-to-lumen permeabilities $(P<0.05)$ does not indicate phosphate secretion, but it is the consequence of technical error frequently obtained in impermeable epithelia during the determination of isotopic permeabilities from lumen-to-bath flux. When lumen-to-bath permeabilities are measured in impermeable epithelia using disappearance of isotope from collected fluid, the drop in collected fluid counts per minute relative to the counts per minute of perfusate can be quite small and even undetectable within the efficiency of the radioactive counting apparatus. 
TABLE II

Phosphate Permeability in the Thin Descending Limb of Henle's Loop

\begin{tabular}{|c|c|c|c|c|c|}
\hline \multicolumn{3}{|c|}{ Bath-to-lumen } & \multicolumn{3}{|c|}{ Lumen-to-bath } \\
\hline $\begin{array}{c}\text { Exp } \\
\text { no. }\end{array}$ & $\begin{array}{l}\text { Tubular } \\
\text { length }\end{array}$ & $\mathbf{P}_{\mathbf{s z}_{\mathrm{PO}_{4}}}$ & $\begin{array}{l}\text { Exp } \\
\text { no. }\end{array}$ & $\begin{array}{c}\text { Tubular } \\
\text { length }\end{array}$ & $P_{\mathbf{s z}_{\mathrm{PO}_{4}}}$ \\
\hline & $m m$ & $\times 10^{-3} \mathrm{~cm} \cdot \mathrm{s}^{-1}$ & & $m m$ & $\times 10^{-3} \mathrm{~cm} \cdot \mathrm{s}^{-1}$ \\
\hline 1 & 1.14 & 0.04 & 1 & 1.30 & -0.44 \\
\hline 2 & 0.90 & 2.32 & 2 & 0.60 & -0.58 \\
\hline 3 & 1.48 & 2.11 & 3 & 0.70 & 1.10 \\
\hline 4 & 1.30 & 1.12 & 4 & 1.00 & -0.73 \\
\hline 5 & 1.60 & 1.11 & 5 & 1.50 & 0.13 \\
\hline 6 & 1.90 & 0.05 & & & \\
\hline 7 & 1.40 & 1.21 & & & \\
\hline 8 & 1.20 & 0.14 & & & \\
\hline Mean & & 1.01 & Mean & & -0.10 \\
\hline SE & & 0.32 & SE & & 0.33 \\
\hline
\end{tabular}

Permeability was measured by adding $\mathrm{H}^{32} \mathrm{PO}_{4}$ to the perfusate or bath. Perfusion rate was $10 \mathrm{nl} \cdot \mathrm{min}^{-1}$. Each value is the mean of three or more collections from a single tubule.

similar to the ones described above in the calcium experiments. The $\mathrm{C} / \mathrm{P}$ concentration of ${ }^{32} \mathrm{PO}_{4}$ is plotted on the vertical axis, and the $\mathrm{C} / \mathrm{P}$ volume marker is plotted on the horizontal axis. A regression line drawn through the experimental points has a slope of 0.93 with a correlation coefficient of 0.97 indicating that phosphate concentration was raised to the same degree as the volume marker. These experiments show that the descending limb was sufficiently impermeable

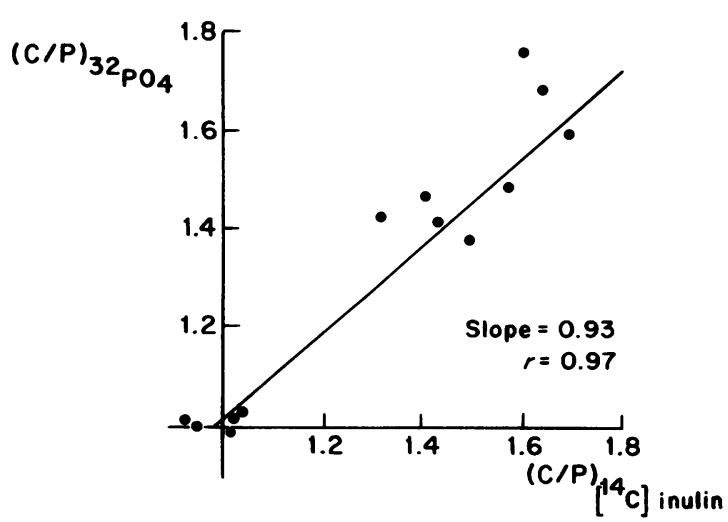

FIGURE 2 Correlation between fractional increase in phosphate concentration $\left([\mathrm{C} / \mathrm{P}]^{45} \mathrm{Ca}\right)$ to fractional increase in volume marker $\left([\mathrm{C} / \mathrm{P}]\left[{ }^{14} \mathrm{C}\right]\right.$-inulin) in the thin descending limb of Henle's loop under conditions of induced net fluid efflux secondary to imposed osmotic gradient. to phosphate so that a transepithelial phosphate gradient could be maintained during osmotic water abstraction.

Thin ascending limb. Calcium and phosphate unidirectional permeabilities were studied in thin ascending limb, and the results are expressed in Table III. The thin ascending limb, like the descending limb, exhibited relatively low permeabilities to these ions: ${ }^{45} \mathrm{Ca} \mathrm{P}_{1 \mathrm{~b}}$ was $1.09 \pm 0.33 \times 10^{-5} \mathrm{~cm} \cdot \mathrm{s}^{-1}$ while ${ }^{45} \mathrm{Ca} \mathrm{P}_{\mathrm{bl}}$ was $1.67 \pm 0.33 \times 10^{-5} \mathrm{~cm} \cdot \mathrm{s}^{-1} ;{ }^{32} \mathrm{PO}_{4} \mathrm{P}_{\mathrm{bl}}$ was $0.67 \pm 0.23 \times 10^{-5} \mathrm{~cm}^{-1}$. Furthermore, there was no significant differences between the two unidirectional ${ }^{45} \mathrm{Ca}$ permeabilities nor between the two unidirectional ${ }^{32} \mathrm{PO}_{4}$ permeabilities. This suggests that neither ion is actively transported in the thin ascending limb.

Since previously the thin ascending limb has been shown to exhibit very high permeabilities to monovalent ions such as $\mathrm{Na}$ and $\mathrm{Cl}$ (13), the apparent ion selectivity was confirmed by determining isotopic bath to lumen permeabilities to ${ }^{32} \mathrm{PO}_{4},{ }^{45} \mathrm{Ca}$, and ${ }^{36} \mathrm{Cl}$ in the same tubules. Table IV clearly shows that the thin ascending limb is one to two orders of magnitude more permeable to chloride than to calcium or phosphate.

Thick ascending limb. Calcium and phosphate transport in the thick ascending limb was examined in segments isolated from the cortex. These tubules were perfused with $\mathrm{NaCl} / \mathrm{HCO}_{3}$ buffer $(\mathrm{pH} 7.4)$ and bathed in identical solutions.

The first set of experiments was designed to determine if there was a net flux of calcium under physiologic perfusion rates. The results presented in

TABLE III

Calcium and Phosphate Permeability in the Thin Ascending Limb of Henle's Loop

\begin{tabular}{|c|c|c|c|c|c|c|c|}
\hline \multicolumn{4}{|c|}{ Lumen-to-bath } & \multicolumn{4}{|c|}{ Bath-to-lumen } \\
\hline $\begin{array}{l}\text { Exp } \\
\text { no. }\end{array}$ & $\begin{array}{l}\text { Tubular } \\
\text { length }\end{array}$ & $P_{32} \mathrm{PO}_{4}$ & $\mathrm{P}_{{ }^{45} \mathrm{Ca}}$ & $\begin{array}{l}\text { Exp } \\
\text { no. }\end{array}$ & $\begin{array}{l}\text { Tubular } \\
\text { length }\end{array}$ & $\mathrm{P}_{\mathbf{S 2}_{\mathrm{PO}_{4}}}$ & $\mathbf{P}_{{ }_{45} \mathrm{ca}}$ \\
\hline & $m m$ & $\times 10^{-5}$ & $m \cdot s^{-1}$ & & $m m$ & $\times 10^{-5} \mathrm{c}$ & $m \cdot s^{-1}$ \\
\hline 1 & 0.30 & & 0.17 & 1 & 0.90 & & 1.90 \\
\hline 2 & 0.50 & 0.53 & 1.64 & 2 & 0.40 & 0.24 & \\
\hline 3 & 0.40 & 0.13 & 1.10 & 3 & 0.50 & 0.41 & 0.97 \\
\hline 4 & 0.40 & 1.88 & 1.98 & 4 & 0.60 & 0.24 & 0.91 \\
\hline \multirow[t]{2}{*}{5} & 0.30 & 0.03 & 0.57 & 5 & 0.50 & 1.27 & 2.69 \\
\hline & & & & 6 & 0.70 & 1.20 & 1.92 \\
\hline Mean & & 0.64 & 1.09 & Mean & & 0.67 & 1.67 \\
\hline SE & & 0.43 & 0.33 & SE & & 0.23 & 0.33 \\
\hline
\end{tabular}

Permeability was measured by adding ${ }^{45} \mathrm{Ca}$ and $\mathrm{H}^{32} \mathrm{PO}_{4}$ to the perfusate or bath. The perfusion rate was $9 \mathrm{nl} \cdot \mathrm{min}^{-1}$. 
TABLE IV

Thin Ascending Limb of Henle's loop

\begin{tabular}{cccr}
\hline \multicolumn{4}{c}{ Bath-to-lumen permeability } \\
\hline Exp & $\mathrm{P}_{{ }_{32} \mathrm{PO}_{4}}$ & ${ }^{\mathrm{P}^{45} \mathrm{Ca}}$ & ${ }{ }^{36_{\mathrm{Cl}}}$ \\
\hline & & $\times 10^{-5} \mathrm{~cm} \cdot \mathrm{s}^{-1}$ & \\
1 & & 1.97 & 109.8 \\
2 & 0.41 & 0.97 & 20.8 \\
3 & 1.27 & 2.69 & 66.9 \\
4 & 1.20 & 1.92 & 27.3 \\
\hline
\end{tabular}

Table $\mathrm{V}$ provide evidence that the thick ascending limb is able to create a calcium lumen to bath concentration gradient. Specific activity of ${ }^{45} \mathrm{Ca}$ was identical to perfusate and bath. Calcium lumen to bath concentration ratio decreased from $0.97 \pm 0.02$ to $0.88 \pm 0.02(P<0.01)$ in the absence of net water movement. The transtubular PD measured simultaneously was $+4.2 \pm 0.6 \mathrm{mV}$ (lumen positive).

In the second set of experiments bidirectional calcium flux was determined by adding successively ${ }^{45} \mathrm{Ca}$ to the bath and to the perfusate (Table VI). Net water reabsorption was not different from zero. The efflux of calcium was $19.96 \pm 1.05 \mathrm{peq} \cdot \mathrm{cm}^{-1}$ $\cdot \mathrm{min}^{-1}$, while the influx was $9.89 \pm 1.23 \mathrm{peq} \cdot \mathrm{cm}^{-1}$ $\cdot \min ^{-1}$. The difference in these two numbers represents the net calcium reabsorption and is equal to $10.07 \pm 1.58 \mathrm{peq} \cdot \mathrm{cm}^{-1} \cdot \mathrm{min}^{-1}$. The observed flux ratio was $2.10 \pm 0.27$ which is significantly higher than the ratio of $1.32 \pm 0.03(P<0.05)$ predicted by the Ussing equation (18):

$$
\frac{\phi l b}{\phi b l}=\frac{(\mathrm{Ca}) l}{(\mathrm{Ca}) \mathrm{b}} \exp \frac{\mathrm{ZFV}}{\mathrm{RT}}
$$

where $\phi$ is the unidirectional flux of calcium from lumen-to-bath (lb) or bath-to-lumen (bl), l and b refer, respectively, to perfusate and bath; $F$ is the Faraday constant; $\mathbf{R}$ the gas constant; $\mathbf{T}$ absolute temperature; $\mathrm{Z}$ is the valence of $\mathrm{Ca}$ and is equal to 2 ; and $\mathrm{V}$ the transtubular electrical potential. The observation of an isotopic flux ratio greater than that predicted by Ussing's equation suggests that the mechanism for calcium transport is more complex than just simple diffusion down an electrical potential gradient.

Another series of experiments was designed to examine the effect of ouabain and transtubular PD on both the efflux and influx of ${ }^{45} \mathrm{Ca}$ across the TALH. It is of interest that ouabain decreased the PD from $+3.5 \pm 0.1$ to $+1.1 \pm 0.3 \mathrm{mV},(P<0.001)$, while the calcium efflux decreased slightly from $29.5 \pm 5.3$ to $23.68 \pm 5.11 \mathrm{peq} \cdot \mathrm{cm}^{-1} \cdot \mathrm{min}^{-1}(P<0.005)$. Therefore, a $67 \pm 7 \%$ reduction in the $P D$ was associated with only a $21 \pm 6 \%$ reduction in calcium efflux. This
TABLE V

Transtubular Calcium Gradient Generated by the Cortical Thick Ascending Limb of Henle

\begin{tabular}{cccccc}
\hline $\begin{array}{c}\text { Exp } \\
\text { no. }\end{array}$ & Length & $\begin{array}{c}\text { Perfusion } \\
\text { rate }\end{array}$ & $(\mathrm{C} / \mathrm{P})_{\mathrm{Ca}++}$ & $(\mathrm{C} / \mathrm{B})_{\mathrm{Ca}++}$ & PD \\
\hline & $m m$ & $n l \cdot \min ^{-1}$ & & & $m V$ \\
1 & 1.90 & 9.0 & 0.89 & 0.89 & +3.9 \\
2 & 1.00 & 4.1 & 0.88 & 0.80 & +3.7 \\
3 & 1.00 & 3.6 & 0.94 & 0.94 & +3.6 \\
4 & 0.80 & 5.4 & 0.92 & 0.90 & +6.6 \\
5 & 1.40 & 1.6 & 0.92 & 0.89 & +3.5 \\
Mean & 1.22 & 4.8 & 0.91 & 0.88 & +4.2 \\
SE & 0.20 & 1.2 & 0.01 & 0.02 & 0.6 \\
\hline
\end{tabular}

$(\mathrm{C} / \mathrm{P})$, collected to perfused fluid concentration ratio; (C/B), collected to bath fluid concentration ratio; $\mathrm{PD}$, transtubular potential different from zero.

constitutes further evidence that the lumen positive $\mathrm{PD}$ in the thick ascending limb is not the major driving force for calcium reabsorption in this segment and that ouabain has only a minimal effect on calcium efflux. Ouabain had no effect on the bath-to-lumen flux of calcium, Table VII.

Phosphate transport in the thick ascending limb was studied in five experiments after the addition of $\mathrm{H}_{2}{ }^{32} \mathrm{PO}_{4}$ to the bath and in four experiments after the addition of the same isotope to the perfusate. The results presented in Table VIII show that ${ }^{32} \mathrm{PO}_{4}$ permeability from lumen to bath was 0.52 $\pm 0.30 \times 10^{-5} \mathrm{~cm} \cdot \mathrm{s}^{-1}$ and not different from ${ }^{32} \mathrm{PO}_{4}$ permeability from bath to lumen, $0.55 \pm 0.14 \times 10^{-5}$ $\mathrm{cm} \cdot \mathrm{s}^{-1}$. These results indicate that the thick ascending limb is relatively impermeable to phosphate and that net phosphate and transport does not take place in this segment of Henle's loop.

TABLE VI

Bidirectional Calcium Fluxes in the Cortical Thick Ascending Limb

\begin{tabular}{|c|c|c|c|c|c|}
\hline Exp & $\phi_{1 \mathrm{~b}}$ & $\phi_{\mathrm{bt}}$ & $\begin{array}{c}\phi_{1 V} / \phi_{\mathrm{bl}} \\
\text { observed }\end{array}$ & $\begin{array}{c}\text { PD } \\
\text { observed }\end{array}$ & $\begin{array}{c}\phi_{1 \mathrm{~d}} / \phi_{\mathrm{bl}} \\
\text { predicted by } \\
\text { Ussing Eq. }\end{array}$ \\
\hline & \multicolumn{2}{|c|}{$\mathrm{peq} \cdot \min ^{-1} \cdot \mathrm{cm}^{-1}$} & & $m V$ & \\
\hline 1 & 20.98 & 9.09 & 2.31 & +4.4 & 1.38 \\
\hline 2 & 18.32 & 6.16 & 2.97 & +4.4 & 1.38 \\
\hline 3 & 18.12 & 9.83 & 1.84 & +3.0 & 1.24 \\
\hline 4 & 18.72 & 13.84 & 1.35 & +3.5 & 1.29 \\
\hline 5 & 23.64 & 10.54 & 2.04 & +3.6 & 1.30 \\
\hline Mean & 19.96 & 9.89 & 2.10 & +3.8 & 1.32 \\
\hline SE & 1.05 & 1.23 & 0.26 & 0.3 & 0.03 \\
\hline
\end{tabular}

Isotopic calcium fluxes were measured by adding ${ }^{45} \mathrm{Ca}$ to the perfusate and bath. The perfusion rate was $10.5 \pm 1.8$. $\phi_{\mathrm{lb}}$, flux lumen-to-bath; $\phi_{\mathrm{bl}}$, flux bath-to-lumen. 
TABLE VII

Effect of Ouabain on Calcium Fluxes in the Cortical Thick Ascending Limb

\begin{tabular}{|c|c|c|c|c|c|c|c|c|c|c|c|}
\hline \multicolumn{6}{|c|}{ Calcium outflux } & \multicolumn{6}{|c|}{ Calcium influx } \\
\hline \multirow{2}{*}{$\begin{array}{l}\text { Exp } \\
\text { no. }\end{array}$} & \multirow{2}{*}{$\begin{array}{l}\text { Tubular } \\
\text { length }\end{array}$} & \multicolumn{2}{|l|}{ Control } & \multicolumn{2}{|l|}{ Ouabain } & \multirow{2}{*}{$\begin{array}{l}\text { Exp } \\
\text { no. }\end{array}$} & \multirow{2}{*}{$\begin{array}{l}\text { Tubular } \\
\text { length }\end{array}$} & \multicolumn{2}{|l|}{ Control } & \multicolumn{2}{|c|}{ Ouabain } \\
\hline & & $\phi_{1 \mathrm{~b}}$ & PD & $\phi_{1 \mathrm{~b}}$ & PD & & & $\phi_{\mathrm{bl}}$ & PD & $\phi_{\mathrm{b} 1}$ & PD \\
\hline & $m m$ & $\mathrm{peq} \cdot \mathrm{cm}^{-1} \cdot \min ^{-1}$ & $m V$ & $\mathrm{peq} \cdot \mathrm{cm}^{-1} \cdot \min ^{-1}$ & $m V$ & & $m m$ & $\mathrm{peq} \cdot \mathrm{cm}^{-1} \cdot \mathrm{min}^{-1}$ & $m V$ & $\mathrm{peq} \cdot \mathrm{cm}^{-1} \cdot \mathrm{min}^{-1}$ & $m V$ \\
\hline 1 & 0.90 & 28.56 & +3.8 & 26.04 & +1.0 & 1 & 0.70 & 1.69 & +3.2 & 1.24 & +0.8 \\
\hline 2 & 0.90 & 46.08 & +3.4 & 42.12 & +2.1 & 2 & 0.90 & 3.66 & +4.3 & 3.42 & +0.6 \\
\hline 3 & 0.40 & 56.16 & +3.4 & 49.20 & +2.0 & 3 & 1.00 & 8.46 & +3.6 & 7.71 & +0.9 \\
\hline 4 & 1.30 & 11.88 & +3.6 & 11.88 & +0.7 & 4 & 0.80 & 2.84 & +3.5 & 5.43 & +0.5 \\
\hline 5 & 0.64 & 18.12 & +3.0 & 15.00 & +0.8 & 5 & 0.86 & 7.13 & +3.8 & 6.71 & +0.1 \\
\hline 6 & 1.20 & 18.72 & +3.5 & 10.80 & +1.8 & 6 & 1.10 & 7.88 & +4.8 & 7.38 & +0.7 \\
\hline 7 & 0.80 & 29.04 & +4.0 & 18.72 & +0.4 & & & & & & \\
\hline 8 & 0.80 & 27.28 & +3.1 & 15.72 & +0.2 & & & & & & \\
\hline Mean & 0.87 & 29.48 & +3.5 & 23.68 & +1.1 & & 0.89 & 5.28 & +3.9 & 5.31 & +0.6 \\
\hline SE & 0.10 & 5.26 & 0.1 & 5.11 & 0.3 & & 0.06 & 1.18 & 0.2 & 1.04 & 0.1 \\
\hline
\end{tabular}

Calcium fluxes were measured by adding ${ }^{45} \mathrm{Ca}$ to the perfusate and bath. The perfusion rate was $13 \mathrm{nl} / \mathrm{min}$.

$\phi_{\mathrm{lb}}$, flux lumen-to-bath; $\phi_{\mathrm{bl}}$, flux bath-to-lumen.

\section{DISCUSSION}

There are two major technical advantages that the in vitro microperfusion technique has in regard to the characterization of calcium and phosphate transport across the nephron segments that constitute the loop of Henle. First, nephron segments which are composed only of a single epithelial cell type can be examined directly in contrast to those micropuncture studies which measure calcium and phosphate transport between the last accessible portion of the proximal convoluted tubule and the early distal convoluted tubule. Between these two puncture sites there exists at least four different types of epithelial cells: pars recta, DLH, tALH, and TALH. The second major advantage of these studies is that an accurate measurement of ionized calcium and phosphate can be made and, further, that these ions can be kept in identical concentrations in the perfusate and bath. This was accomplished by using identical protein-free solutions as perfusion and bathing solutions. $^{3}$ Thus, the unidirectional isotopic permeation numbers can be used to calculate the unidirectional flux values.

Previous micropuncture studies have generally indicated that less calcium reaches the early distal tubules than was present at the last accessible portion of the proximal convoluted tubule $(1,3-8)$ while no net movement of phosphate occurs between these two points (3-8). The present studies extend these previous studies and show that: (1) the passive permeability to calcium and phosphate in all seg-

\footnotetext{
${ }^{3}$ It is well appreciated that protein may influence the effective ionic concentration of calcium and phosphate via binding and Donnan effects.
}

ments of the loop of Henle is exceedingly low; (2) no net movement of phosphate occurs across any segment of the loop of Henle; and (3) calcium transport across the TALH cannot be explained by purely passive mechanisms.

Since previous micropuncture studies have not shown net movement of phosphate across the loop of Henle, it was not surprising that the present studies demonstrated that the DLH is relatively impermeable to phosphate; (Table II) even though it might be argued that the micropuncture studies may have represented counterbalancing effects of phosphate reabsorption and secretion by different segments of the loop. The published information in regard to calcium transport by the DLH is less clear. Though all studies have shown that the tubular fluid-toplasma calcium concentration is higher in the fluid obtained from the bend of the loop than the fluid collected from end proximal convoluted tubule, Jamison et al. (19) have recently shown that net reabsorption of calcium occurs between these puncture points. It must be remembered, however, that the micropuncture techniques are not sampling fluid from the same tubules when obtaining fluid from proximal convoluted tubules in superficial cortex and comparing it to fluid from descending limb of Henle which are connected to juxtamedullary proximal tubules. Even if fluid was sampled from the same tubule, it is quite possible, as Jamison et al. (19) suggest, that the net calcium reabsorption may have occurred in the pars recta. Thus the previous in vivo studies are not at variance with the present in vitro studies which show that calcium is relatively impermeable across the DLH, Table I, and that both calcium, Fig. 1, and phosphate, Fig. 2, are raised to a 
higher concentration by virtue of water abstraction when these segments are perfused in bathing fluid made hyperosmolal by addition of $\mathrm{NaCl}$ to the bath. It is of interest that the present studies with calcium and phosphate are strikingly similar to the previous in vitro perfusion studies which revealed that the DLH is essentially impermeable also to $K(20)$, Na (21), and urea (22) while being highly permeable to water (21). Thus, if these rabbit in vitro studies are representative of in vivo conditions, it may be concluded that all of the tested solutes are further concentrated in the DLH by osmotic abstraction of water.

There are no previous studies measuring calcium and phosphate transport across the thin ascending limb of Henle. Also, only a few in vitro studies have examined the transport characteristics of tALH. This is an exceedingly difficult segment to dissect, and it therefore is important to validate that the studies were indeed conducted using segments of tALH instead of DLH. This was accomplished in a group of tubules in which ${ }^{45} \mathrm{Ca},{ }^{32} \mathrm{PO}_{4}$, and ${ }^{36} \mathrm{Cl}$ permeability coefficients were measured simultaneously, Table IV. Imai and Kokko (13) have previously shown that the ${ }^{36} \mathrm{Cl}$ permeability of the tALH is quite high and, further, that the high ${ }^{36} \mathrm{Cl}$ permeation does not follow the predictions of simple passive diffusion (23). The present studies indeed did confirm the presence of high chloride permeability and, therefore, gave us assurance that the segments we were studying were, in fact, segments of tALH. Our current results indicate that the bidirectional permeabilities for calcium and phosphate are bidirectionally equal and both show that the tALH is relatively impermeable to calcium and phosphate, Table III and IV. Thus, in contrast to the high permeability of the tALH to ${ }^{22} \mathrm{Na}$ and ${ }^{36} \mathrm{Cl}$, the tALH is essentially impermeable to calcium and phosphate thus suggesting that no net movement of these two latter ions occurs across the tALH.

Similar to the thin ascending limb of Henle, no previous studies have directly examined the characteristics of phosphate or calcium transport across the thick ascending limb of Henle. This segment is of particular interest since Rocha and Kokko (17) and Burg and Green (24) have previously shown that salt is transported out of this segment as a consequence of an active chloride pump, therefore generating a lumen positive potential difference. The present studies confirm the previously demonstrated positive potential difference when these segments are perfused with fluid similar to the bath, Table V. Furthermore, the results with respect to phosphate transport can be easily discussed by the results in Table VIII which show that the phosphate permeability, and therefore fluxes, in both directions are exceedingly low and therefore consistent with previous in vivo studies demonstrating no net phosphate movement across the loop of Henle.

Calcium transport across the thick ascending limb of Henle, however, differs from phosphate transport across this same segment. First, it was shown that lumen-to-bath flux of calcium was approximately twice as great as the bath-to-lumen flux when measured in the same tubule, Table VI. Furthermore, it was shown that the TALH is able to generate a significant concentration gradient for calcium when perfused with solutions with calcium concentration identical to the bath, Table V. Thus the studies suggested that calcium is transported across the TALH by some mechanism other than simple passive diffusion.

The nature of calcium transport across the TALH was further examined by two different techniques: (a) comparing calcium flux ratio and the trastubular PD with the Ussing's equation; and $(b)$ examining the effect of ouabain on the calcium efflux.

TABLE VIII

Apparent Isotopic Permeability Coefficient for Phosphate in the Thick Ascending Limb

\begin{tabular}{|c|c|c|c|c|c|c|c|c|c|}
\hline \multicolumn{5}{|c|}{ Lumen-to-bath } & \multicolumn{5}{|c|}{ Bath-to-lumen } \\
\hline $\begin{array}{l}\text { Exp } \\
\text { no. }\end{array}$ & $\begin{array}{l}\text { Tubular } \\
\text { length }\end{array}$ & $\mathrm{Vi}$ & $\mathrm{P}_{32} \mathrm{PO}$ & PD & $\begin{array}{l}\text { Exp } \\
\text { no. }\end{array}$ & $\begin{array}{l}\text { Tubular } \\
\text { length }\end{array}$ & Vi & $\mathrm{P}_{32 \mathrm{PO}}$ & \\
\hline & & $n l \cdot \min ^{-1}$ & $\times 10^{-3} \mathrm{~cm} \cdot \mathrm{s}^{-}$ & $m V$ & & & $n l \cdot \min ^{-1}$ & $\times 10^{-5} \mathrm{~cm} \cdot \mathrm{s}^{-1}$ & $m V$ \\
\hline 1 & 0.80 & 5.2 & 0.01 & 3.5 & 1 & 0.64 & 17.2 & 1.05 & 4.2 \\
\hline 2 & 1.40 & 5.9 & 1.21 & 4.0 & 2 & 0.85 & 13.8 & 0.58 & 3.3 \\
\hline 3 & 0.55 & 14.6 & 0.84 & 4.0 & 3 & 1.60 & 10.1 & 0.16 & 4.2 \\
\hline 4 & 1.00 & 11.9 & 0.03 & 3.0 & 4 & 0.70 & 8.2 & 0.49 & 4.5 \\
\hline Mean & & & 0.52 & 3.6 & & & & 0.55 & 4.2 \\
\hline SE & & & 0.30 & 0.2 & & & & 0.14 & 0.2 \\
\hline
\end{tabular}

The permeabilities are not corrected for PD.

$\mathrm{Vi}$, perfusion rate; $\mathrm{PD}$, transtubular potential difference. 
It is generally accepted that active transport of mass across an epithelium exists if the transport occurs against an electrochemical potential difference and if the movement of this mass occurs in the absence of an external driving force. However, it is more difficult to demonstrate active transport down a potential gradient. We have previously shown that the transtubular PD of an isolated perfused TALH is oriented in such a way that the lumen is positive (17) a finding which was confirmed in the present series of studies, Tables V-VIII. Thus the active chloride pump which generates the positive potential difference may, in part, act as a driving force for efflux of calcium. If the unidirectional flux ratios are in agreement with the flux ratios as predicted by the Ussing's equation using the measured transtubular PD's, then it is not necessary to postulate the existance of active transport processes. On the other hand, if the lumen-to-bath over bath-to-lumen flux ratio is greater than would be predicted by the Ussing's equation, then it would be necessary to postulate the existance of some transport process which does not follow the simple laws of passive diffusion. The results of the present studies, Table VI, clearly show that the efflux of calcium is significantly greater than is the influx of calcium as predicted by the Ussing's equation. This would suggest that some membrane interactive process is taking place which is capable of decreasing the calcium to lumen-to-bath concentrations to 0.88 , Table $\mathrm{V}$. It is difficult to compare the capacity of the calcium transport system to the previously reported capacity of the chloride pump. The present $\mathrm{Ca}^{++}$lumen-to-bath ratio of 0.88 is higher than the previously reported (17) $\mathrm{Cl}$ lumen-to-bath ratio of 0.77 , however, the luminal fluid contact time was longer in the chloride experiment. Furthermore, the chloride concentration is decreased against a potential gradient while the calcium concentration is decreased down a favorable potential gradient.

We next examined the effect of ouabain on the efflux and influx of calcium across the TALH. In previous studies we have shown that $10 \mu \mathrm{M}$ ouabain reversibly decreased the magnitude of the transtubular PD (17). Similarly in the present studies $10 \mu \mathrm{M}$ ouabain, when added to the bath, decreased the transtubular PD, Table VII. There was a slight but significant $(P<0.01)$ decrease in the unidirectional lumento-bath flux of $\mathrm{Ca}^{++}$, Table VIII. It is of interest that the efflux of calcium did not decrease to the same level as the influx (bath-to-lumen), and further, that ouabain had no apparent effect on the influx of calcium, Table VII. Thus these results strongly suggest that calcium transport across the TALH is by some other mechanism than by simple diffusion, and further, unlike chloride transport, this mechanism is not as sensitive to ouabain.
In summary, the present studies are the first to examine directly the characteristics of calcium and phosphate transport across those nephron segments which make up the loops of Henle. In these studies it was shown that no net transport of phosphate or calcium occurs across either the thin descending or thin ascending limb of Henle and also that no net phosphate transport could be demonstrated across the thick ascending limb of Henle. Furthermore, it was shown that the thick ascending limb of Henle does have the capacity for net reabsorption of calcium which is not affected to a major degree by ouabain. However, it must be remembered that all of these findings were obtained by perfusing isolated nephron segments of rabbit in vitro, and it is not known whether these results can be extended to in vivo conditions.

\section{ACKNOWLEDGMENTS}

The authors are indebted to Dr. Harry Jacobson for helpful suggestions in the preparation of this manuscript.

This investigation was supported by grants from Fundacao de Amparo a Pesquisa do Estado de Sao Paulo; U. S. Public Health Service Program Project grant PO1 HL 11662; and National Institute of Arthritis and Metabolic Diseases Research grant 1 RO1 AM 14677.

\section{REFERENCES}

1. Lassiter, W. E., C. W. Gottschalk, and M. Mylle. 1963. Micropuncture study of renal tubular reabsorption of calcium in normal rodents. Am. J. Physiol. 204: 771-775.

2. Durate, C. G., and J. F. Watson. 1967. Calcium reabsorption in the proximal tubule of the dog nephron. Am.J. Physiol. 212: 1355-1360.

3. Murayama, Y., F. Morel, and C. Le Grimellec. 1972. Phosphate, calcium and magnesium transfers in proximal tubules and loops of Henle, as measured by single nephron microperfusion experiments in the rat. Pfluegers Arch. Eur. J. Physiol. 333: 1-16.

4. Le Grimellec, C., N. Roinel, and F. Morel. 1973. Simultaneous $\mathrm{Mg}, \mathrm{Ca}, \mathrm{P}, \mathrm{K}, \mathrm{Na}$ and $\mathrm{Cl}$ analysis in rat tubular fluid. I. During perfusion of either Inulin or Ferrocyanide. Pfluegers Arch. Eur. J. Physiol. 340: 181-196.

5. Edwards, B. R., P. G. Baer, R. A. L. Sutton, and J. H. Dirks. 1973. Micropuncture study of diuretic effects on sodium and calcium reabsorption in the dog nephron. J. Clin. Invest. 52: 2418-2427.

6. Kuntziger, H., C. Amiel, N. Roinel, and F. Morel. 1974. Effects of parathyroidectomy and cyclic AMP on renal transport of phosphate, calcium, and magnesium. Am. J. Physiol. 227: 905-911.

7. Le Grimellec, C., N. Roinel, and F. Morel. 1974. Simultaneous $\mathrm{Mg}, \mathrm{Ca}, \mathrm{P}, \mathrm{K}, \mathrm{Na}$ and $\mathrm{Cl}$ analysis in rat tubular fluid. IV. During acute phosphate plasma loading. Pfluegers Arch. Eur. J. Physiol. 346: 189-204.

8. Amiel, C., H. Kuntziger, and G. Richet. 1970. Micropuncture study of handling of phosphate by proximal and distal nephron in normal and parathyroidectomized rat. Evidence for distal reabsorption. Pfluegers Arch. Eur. J. Physiol. 317: 93-109.

9. Bank, N., H. S. Aynedjian, and S. W. Weinstein. 1974. A microperfusion study of phosphate reabsorption by the 
rat proximal renal tubule. Effect of parathyroid hormone. J. Clin. Invest. 54: 1040-1048.

10. Le Grimellec, C. 1975. Micropuncture study along the proximal convoluted tubule. Electrolyte reabsorption in first convolutions. Pfluegers Arch. Eur. J. Physiol. 354: 133-150.

11. Ullrich, K. J., G. Rumrich, and G. Fuchs. 1964. Wasserpermeabilität und transtubulärer Wasserfluss corticater Nephronabschnitte bei verschiedenen Diuresezuständen. Pfluegers Arch. Eur. J. Physiol. 280: 99-119.

12. Burg, M., J. Grantham, M. Abramow, and J. Orloff. 1966. Preparation and the study of fragments of single rabbit nephrons. Am. J. Physiol. 210: 1293-1298.

13. Imai, M., and J. P. Kokko. 1974. Sodium chloride, urea, and water transport in the thin ascending limb of Henle. Generation of osmotic gradients by passive diffusion of solutes. J. Clin. Invest. 53: 393-402.

14. Schaer, H. 1974. Decrease in ionized calcium and bicarbonate in physiological solutions. Pfluegers Arch. Eur. J. Physiol. 347: 249-254.

15. Grantham, J. J., and M. B. Burg. 1966. Effect of vasopressin and cyclic AMP on permeability of isolated collecting tubules. Am. J. Physiol. 211: 255-259.

16. Imai, M., and J. P. Kokko. 1972. Effect of peritubular protein concentration on reabsorption of sodium and water in isolated perfused proximal tubules. J. Clin. Invest. 51: 314-325.
17. Rocha, A. S., and J. P. Kokko. 1973. Sodium chloride and water transport in the medullary thick ascending limb of Henle. Evidence for active chloride transport. J. Clin. Invest. 52: 612-623.

18. Ussing, H. H. 1950. Distinction by means of tracers between active transport and diffusion. The transfer of iodide across the isolated frog skin. Acta Physiol. Scand. 19: $43-56$.

19. Jamison, R. L., N. R. Frey, and F. B. Lacy. 1974. Calcium reabsorption in the thin loop of Henle. Am. J. Physiol. 227: 745-751.

20. Rocha, A. S., and J. P. Kokko. 1973. Membrane characteristics regulating potassium transport out of the isolated perfused descending limb of Henle. Kidney Int. 4: 326-330.

21. Kokko, J. P. 1970. Sodium chloride and water transport in the descending limb of Henle. J. Clin. Invest. 49: 1838-1846.

22. Kokko, J. P. 1972. Urea transport in the proximal tubule and the descending limb of Henle. J. Clin. Invest. 51: 1999-2008.

23. Imai, M., and J. P. Kokko. 1976. Mechanism of sodium and chloride transport in the thin ascending limb of Henle. J. Clin. Invest. 58: 1054-1060.

24. Burg, M. B., and N. Green. 1973. Function of the thick ascending limb of Henle's loop. Am. J. Physiol. 224: 659-668. 